\title{
Isolation and NMR Spectral Assignments of 18-Glycyrrhetinic acid-3-O-D-glucuronide and 18-Glycyrrhetinic acid
}

\author{
Venkata Sai Prakash Chaturvedula ${ }^{1}$, Oliver $\mathrm{Yu}^{2}$, and Guohong Mao ${ }^{3}$ \\ ${ }^{1,}$ Natural Ingredient Development, Blue California, 30111 Tomas, Rancho Santa Margarita, \\ CA 92688, USA \\ 2, Wuxi New Way Biotechnology, 401 North Xingyuan Road, Wuxi 210043, P.R. China.
}

\begin{abstract}
Two olenane triterpenes, 18 $\beta$-glycyrrhetinic acid-3-O- $\beta$-D-glucuronide and $18 \beta$-glycyrrhetinic acid were obtained from the acid hydrolysis of $18 \beta$-glycyrrhetinic acid-3-O- $\beta$-D-glucuronopyranosyl- $(1 \rightarrow 2)-\beta$ $D$-glucuronide (Glycyrrhizic acid or Glycyrrhizin), a triterpene glucuronide isolated from the commercial extract of the roots of Glycyrrhia glabra. The complete ${ }^{1} \mathrm{H}$ and ${ }^{13} \mathrm{C} N M R$ assignments of the two triterpenes $18 \beta$ glycyrrhetinic acid-3-O- $\beta$-D-glucuronide and 18B-glycyrrhetinic acid were achieved on the basis of extensive $1 D$ and $2 D N M R\left({ }^{1} \mathrm{H}\right.$ and ${ }^{13} \mathrm{C}, \mathrm{COSY}, \mathrm{HSQC}$, and $\left.\mathrm{HMBC}\right)$ as well as mass spectral data.
\end{abstract}

KEYWORDS: Glycyrrhiza glabra, Fabaceae, Glycyrrhizin, Triterpene glucuronide, Hydrolysis products, $1 D$ and $2 D$ NMR spectral data, Structure characterization.

\section{INTRODUCTION}

The triterpenoid saponin, glycyrrhizic acid (glycyrrhizin) was the major bio-active constituent isolated from the roots of Glycyrrhiza glabra (Fabaceae), which is a sweet-tasting material and is about 50 times sweeter than sugar, making it a widely used as a sweetening additive in the food industry [1-3]. The structure of glycyrrhizin has been characterized as $18 \beta$-glycyrrhetinic acid-3-O- $\beta$ - $D$-glucuronopyranosyl- $(1 \rightarrow 2)-\beta-D-$ glucuronide (1) on the basis of NMR and mass spectral data as well as hydrolysis studies [4-5]. G. glabra also known as Licorice is a well-known medicinal herb that grows in various parts of the world, and is one of the oldest and widely used herbs known both in western and eastern countries since several thousand years ago [24]. Licorice has been used in the traditional system of medicine: the roots and rhizomes of G. glabra have various pharmaceuticals activities like antispasmodic, demulcent, pectoral, anti-inflammatory, antiulcer, expectorant, antimicrobial and anxiolytic activities as well as a flavoring agent to disguise the unpleasant flavor of other medications [3-4].

As a part of our continuing research to discover natural products, we have isolated several diterpene glycosides from the commercial extracts of the leaves of S. rebaudiana [6-9], flavonoids from Hovenia dulcis [10], and triterpenes from Glycyrrhia glabra [5]. The structures of the isolated compounds were characterized on the basis of extensive 1D $\left({ }^{1} \mathrm{H}\right.$ and $\left.{ }^{13} \mathrm{C}\right)$ and 2D (COSY, HSQC and HMBC) NMR as well as high resolution mass spectroscopic data and chemical modifications. In this paper, we are describing the isolation, and proton as

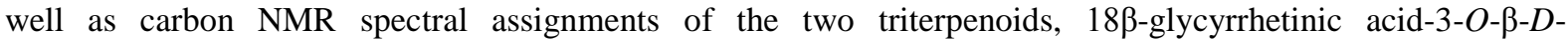
glucuronide (2) and 18ß-glycyrrhetinic acid (3) that were obtained from the acid hydrolysis of the triterpene glycoside $18 \beta$-glycyrrhetinic acid-3- $O-\beta-D$-glucuronopyranosyl-( $(1 \rightarrow 2)-\beta$ - $D$-glucuronide $(\mathbf{1})$ isolated from the commercial extract of the roots of G. glabra, The structures of compounds $\mathbf{2}$ and $\mathbf{3}$ were achieved on the basis of 1D $\left({ }^{1} \mathrm{H}\right.$ and $\left.{ }^{13} \mathrm{C}\right)$ and 2D (COSY, HSQC and HMBC) NMR and high resolution mass spectroscopic (MS) data, as well as by comparison of the physical and spectral data of reported in literature.

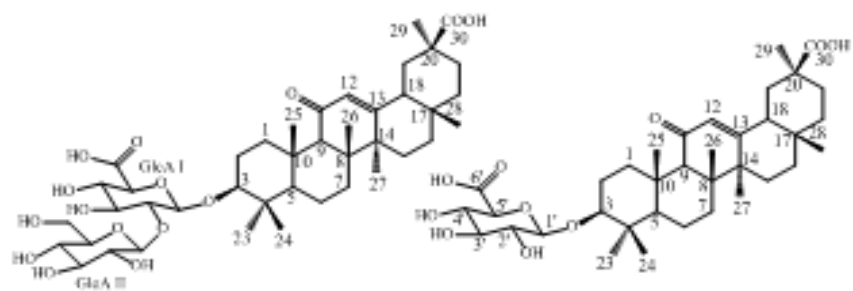

1

2

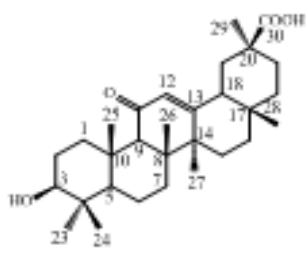

3

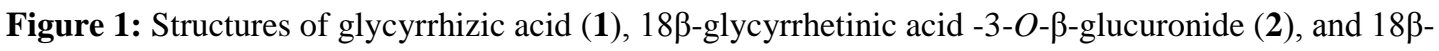
glycyrrhetinic acid (3) 


\begin{abstract}
II. EXPERIMENTAL
General Instrumentation Methods

IR spectral data was acquired using a Perkin Elmer 400 Fourier Transform Infrared (FT-IR) Spectrometer with Universal attenuated total reflectance (UATR) polarization accessory. HPLC analysis was performed using a Dionex UPLC ultimate 3000 system (Sunnyvale, CA), including a quaternary pump, a temperature controlled column compartment, an auto sampler and a UV absorbance detector. Phenomenex Luna C18 reversed-phase with guard column, $150 \times 4.6 \mathrm{~mm}, 3 \mu \mathrm{m}(100 \mathrm{~A})$ were used for the isolation and purification of glycyrrhizin (1). NMR spectra were acquired on Bruker Avance DRX $500 \mathrm{MHz}$ or Varian INOVA $600 \mathrm{MHz}$ instrument instruments using standard pulse sequences. The NMR spectra were performed in $\mathrm{C}_{5} \mathrm{D}_{5} \mathrm{~N}$; chemical shifts are given in $\delta(\mathrm{ppm})$, and coupling constants are reported in Hz. MS and MS/MS data were generated with a Thermo LTQ-FTMS mass spectrometer (100,000 resolutions) equipped with a Nano spray ionization source. Samples were diluted with methanol and introduced via infusion using the onboard syringe.
\end{abstract}

\title{
Isolation and Characterization
} earlier [5].

Compound 1 was purified from the commercial aqueous alcoholic extract of G. glabra root as reported

\section{Partial hydrolysis of 1 using Oxalic acid}

Compound $1(50 \mathrm{mg})$ was treated with $50 \mathrm{mg}$ oxalic acid in $20 \mathrm{ml}$ of 1:1 MeOH:water and the mixture was heated at $60^{\circ} \mathrm{C}$ for 24 hours. The reaction mixture was extracted with ethyl acetate (EtOAc) $(2 \times 250 \mathrm{ml})$ to give an aqueous fraction containing sugars and an EtOAc fraction containing the partial hydrolyzed product. Concentration of the EtOAC fraction followed by purification using normal phase PTLC using the solvent system n-hexane/EtOAC (70:30) yielded a white which has been identified as 18ß-glycyrrhetinic acid-3-O- $\beta-D$ glucuronide (2) on the basis of NMR and Mass spectral data [11].

\section{8ß-glycyrrhetinic acid-3- $O$-- $D$-glucuronide (2)}

White powder; IR $v_{\max }: 3318,2960,2905,1678,1530,1150,1054,913 \mathrm{~cm}^{-1} ;{ }^{1} \mathrm{H}-\mathrm{NMR}(600 \mathrm{MHz}$, $\left.\mathrm{C}_{5} \mathrm{D}_{5} \mathrm{~N}, \delta \mathrm{ppm}\right)$ and ${ }^{13} \mathrm{C}-\mathrm{NMR}\left(150 \mathrm{MHz}, \mathrm{C}_{5} \mathrm{D}_{5} \mathrm{~N}, \delta \mathrm{ppm}\right)$ spectroscopic data see Table 1; HRMS $(\mathrm{M}+\mathrm{H})^{+} \mathrm{m} / \mathrm{z}$ 647.3782 (calcd. for $\mathrm{C}_{36} \mathrm{H}_{55} \mathrm{O}_{10}$ : 647.3795).

\section{Acid hydrolysis of 1 using Sulfuric acid}

To a solution of compound $1(50 \mathrm{mg})$ in $\mathrm{MeOH}(25 \mathrm{ml})$ was added $100 \mathrm{ml}$ of $10 \% \mathrm{H}_{2} \mathrm{SO}_{4}$ in $\mathrm{MeOH}$ and the mixture was refluxed for 72 hours. The reaction mixture was then extracted with ethyl acetate (EtOAc) $(2 \mathrm{x}$ $250 \mathrm{ml}$ ) and concentration of the organic fraction yielded an aglycone, which has been identified as glycyrrhetinic acid (3) on the basis of spectral data and co-TLC with standard compound [12].

\section{8ß-glycyrrhetinic acid (3)}

White powder; IR $v_{\max }: 3315,2956,2908,1676,1524,1155,1053,910 \mathrm{~cm}^{-1} ;{ }^{1} \mathrm{H}-\mathrm{NMR}(600 \mathrm{MHz}$, $\left.\mathrm{C}_{5} \mathrm{D}_{5} \mathrm{~N}, \delta \mathrm{ppm}\right)$ and ${ }^{13} \mathrm{C}-\mathrm{NMR}\left(150 \mathrm{MHz}, \mathrm{C}_{5} \mathrm{D}_{5} \mathrm{~N}, \delta \mathrm{ppm}\right)$ spectroscopic data see Table 1; HRMS $(\mathrm{M}+\mathrm{H})^{+} \mathrm{m} / \mathrm{z}$ 471.3462 (calcd. for $\mathrm{C}_{30} \mathrm{H}_{47} \mathrm{O}_{4}: 471.3474$ ).

\section{Results and Discussion}

Compound 2 was isolated as a colorless powder and its positive mode of ESI Time of Flight (TOF) mass spectrum indicated an $[\mathrm{M}+\mathrm{H}]^{+}$ion at $\mathrm{m} / z 647.3782$ which was in good agreement with the molecular formula $\mathrm{C}_{36} \mathrm{H}_{54} \mathrm{O}_{10}$; the chemical composition was further supported by the ${ }^{13} \mathrm{C}$ NMR spectral data. Liebermann-Burchard reaction indicated compound $\mathbf{2}$ is having a terpenoid skeleton [13], as in $\mathbf{1}$. The ${ }^{1} \mathrm{H}$ NMR spectra of compound $\mathbf{2}$ showed the presence of seven methyl sinlgets at $\delta 0.79,1.06,1.23,1.29,1.38,1.41$ and 1.45 , and a signal corresponding to the $\mathrm{H}-3$ of the oxymethine proton which was appeared as a doublet of doublets at $\delta 3.35$. The ${ }^{1} \mathrm{H}$ NMR spectra of compound 2 also showed the presence of a singlet at $\delta$ 5.96 corresponding to the presence of a olefinic proton of a trisubstituted double bond. Further, the ${ }^{13} \mathrm{C}$ NMR spectral data of 2 showed the presence of a carbonyl group resonating at $\delta 200.0$ which showedan HMBC correlation to the trisubstituted olefinic proton resonating at $\delta 5.96$ indicated the presence of an $\alpha, \beta$-unstaurated carbonyl group in compound $\mathbf{2}$. The above spectral data of $\mathbf{2}$ suggested the presence of an oleanane triterpene skeleton having a hydroxyl group at C-3 position with a double bond at C-12/C-13 and seven methyl groups. Also, the ${ }^{1} \mathrm{H}$ NMR spectrum of 2 showed an anomeric proton at $\delta 5.43$ as doublets indicating the presence of a sugar unit in its structure. The presence of four secondary hydroxyl groups together with anomeric carbon and a carboxylic carbonyl group in the ${ }^{13} \mathrm{C}$ NMR spectral data of 2 suggested the presence of glucuronic acid as the sugar unit in its structure. The large coupling constant observed for the anomeric proton of the glucuronic acid moiety at $\delta 5.43(\mathrm{~d}, J=8.1 \mathrm{~Hz})$, suggested its $\beta$-orientation as reported earlier for glycyrrhizin. The ${ }^{1} \mathrm{H}$ and ${ }^{13} \mathrm{C}$ NMR values for all the protons and carbons were assigned on the basis of COSY, HMQC and HMBC correlations and were given in Table 1. 
Isolation and NMR Spectral Assignments of...

Table 1. ${ }^{1} \mathrm{H}$ and ${ }^{13} \mathrm{C}$ NMR chemical shift values for compounds 2 and $\mathbf{3}$ recorded in $\mathrm{C}_{5} \mathrm{D}_{5} \mathrm{~N}^{\mathrm{a}-\mathrm{c}}$.

\begin{tabular}{|c|c|c|c|c|}
\hline \multirow{3}{*}{$\begin{array}{l}\text { Position } \\
1\end{array}$} & \multicolumn{2}{|c|}{2} & \multicolumn{2}{|c|}{$\mathbf{3}$} \\
\hline & \multicolumn{2}{|c|}{${ }^{1} \mathrm{H}$ NMR $\quad{ }^{13} \mathrm{C}$ NMR } & \multicolumn{2}{|c|}{${ }^{1} \mathrm{H}$ NMR $\quad{ }^{13} \mathrm{C}$ NMR } \\
\hline & $\begin{array}{l}0.97 \mathrm{~m}, 3.08 \mathrm{dt}(J=7.6 \text {, } \\
8.9)\end{array}$ & 39.7 & $0.96 \mathrm{~m}, 3.24 \mathrm{dt}(J=7.8,9.1)$ & 38.9 \\
\hline 2 & $1.78 \mathrm{~m}, 2.06 \mathrm{~m}$ & 27.0 & $1.76 \mathrm{~m}, 2.04 \mathrm{~m}$ & 29.0 \\
\hline 3 & $3.35 \mathrm{dd}(J=5.7,12.1)$ & 89.2 & $3.52 \mathrm{dd}(J=5.1,12.4)$ & 78.4 \\
\hline 4 & - & 40.3 & - & 40.3 \\
\hline 5 & $0.84 \mathrm{~m}$ & 55.7 & $0.90 \mathrm{~m}$ & 55.8 \\
\hline 6 & $1.44 \mathrm{~m}, 1.72 \mathrm{~m}$ & 18.0 & $1.47 \mathrm{~m}, 1.74 \mathrm{~m}$ & 18.5 \\
\hline 7 & $1.48 \mathrm{~m}, 1.74 \mathrm{~m}$ & 33.2 & $1.49 \mathrm{~m}, 1.76 \mathrm{~m}$ & 33.5 \\
\hline 8 & - & 43.7 & - & 44.0 \\
\hline 9 & $2.47 \mathrm{~s}$ & 62.5 & $2.57 \mathrm{~s}$ & 62.7 \\
\hline 10 & - & 37.8 & - & 38.2 \\
\hline 11 & - & 200.0 & - & 200.2 \\
\hline 12 & $5.96 \mathrm{~s}$ & 129.0 & $6.04 \mathrm{~s}$ & 129.2 \\
\hline 13 & - & 172.9 & - & 170.2 \\
\hline 14 & - & 46.0 & - & 46.1 \\
\hline 15 & $1.26 \mathrm{~m}, 2.15 \mathrm{~m}$ & 27.0 & $1.26 \mathrm{~m}, 2.17 \mathrm{~m}$ & 27.2 \\
\hline 16 & $1.06 \mathrm{~m}, 2.17 \mathrm{~m}$ & 27.2 & $1.05 \mathrm{~m}, 2.18 \mathrm{~m}$ & 27.4 \\
\hline 17 & - & 32.5 & - & 32.7 \\
\hline 18 & $2.18 \mathrm{~m}$ & 49.1 & $2.20 \mathrm{~m}$ & 49.3 \\
\hline 19 & $1.52 \mathrm{~m}, 2.37 \mathrm{~m}$ & 42.1 & $1.47 \mathrm{~m}, 2.31 \mathrm{~m}$ & 42.2 \\
\hline 20 & - & 44.5 & - & 44.6 \\
\hline 21 & $1.55 \mathrm{~m}, 2.12 \mathrm{~m}$ & 32.0 & $1.50 \mathrm{~m}, 2.10 \mathrm{~m}$ & 32.0 \\
\hline 22 & $1.32 \mathrm{~m}, 1.76 \mathrm{~m}$ & 38.8 & $1.31 \mathrm{~m}, 1.74 \mathrm{~m}$ & 38.9 \\
\hline 23 & $1.23 \mathrm{~s}$ & 28.6 & $1.16 \mathrm{~s}$ & 28.7 \\
\hline 24 & $0.79 \mathrm{~s}$ & 17.0 & $0.83 \mathrm{~s}$ & 17.1 \\
\hline 25 & $1.29 \mathrm{~s}$ & 17.2 & $1.30 \mathrm{~s}$ & 17.4 \\
\hline 26 & $1.38 \mathrm{~s}$ & 19.2 & $1.37 \mathrm{~s}$ & 19.4 \\
\hline 27 & $1.41 \mathrm{~s}$ & 24.0 & $1.38 \mathrm{~s}$ & 24.0 \\
\hline 28 & $1.06 \mathrm{~s}$ & 29.1 & $1.11 \mathrm{~s}$ & 29.2 \\
\hline 29 & $1.45 \mathrm{~s}$ & 29.2 & $1.43 \mathrm{~s}$ & 29.3 \\
\hline 30 & & 179.5 & & 179.6 \\
\hline $1^{\prime}$ & $5.43 \mathrm{~d}(J=8.1)$ & 107.5 & & \\
\hline $2^{\prime}$ & $4.12 \mathrm{dd}(J=7.8,8.4)$ & 78.5 & & \\
\hline $3^{\prime}$ & $4.04 \mathrm{dd}(J=8.1,8.4)$ & 78.2 & & \\
\hline $4^{\prime}$ & $4.23 \mathrm{t}(J=8.1)$ & 75.9 & & \\
\hline $5^{\prime}$ & $4.46 \mathrm{t}(J=8.4)$ & 73.8 & & \\
\hline $6^{\prime}$ & & 170.1 & & \\
\hline
\end{tabular}

a assignments made on the basis of COSY, HSQC and HMBC correlations; ${ }^{\mathrm{b}}$ Chemical shift values are in $\delta(\mathrm{ppm}) ;{ }^{\mathrm{c}}$ Coupling constants are in Hz.

In the absence of eighth methyl group and the appearance of a carbonyl group resonating at $\delta 179.5$ in the ${ }^{13} \mathrm{C}$ NMR spectral data of $\mathbf{2}$ suggested the presence of an acid functional group similar to $\mathbf{1}$. The presence of the carboxylic acid group was identified at C-30 position by the key HMBC correlations as shown in Figure 2. Based on the results from 1D and 2D NMR spectral data, it was concluded that the structure of 2 has a triterpene aglycone moiety with an $\alpha, \beta$-unsaturated carbonyl group, a carboxylic acid group, seven methyl singlets and one $\beta$-D-glucuronyl unit. Thus, the structure of 2 was assigned as the known compound 18 $\beta$-glycyrrhetinic acid-3$O-\beta$ - $D$-glucuronide; NMR and mass spectral data are consistent to the reported literature values [11].

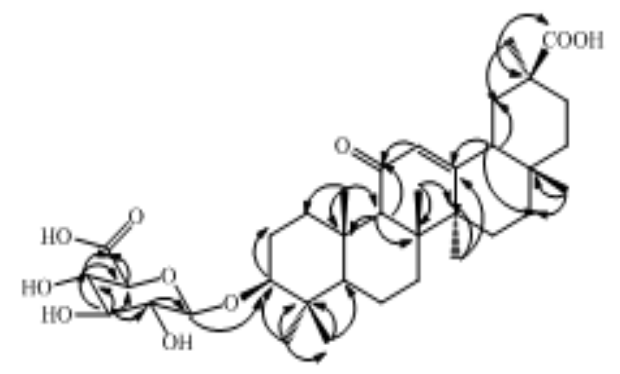

Figure 2: Key HMBC correlations of $18 \beta$-glycyrrhetinic acid-3- $O$ - $\beta$ - $D$-glucuronide (2) 
Compound 3 was also isolated as a colorless powder and its molecular formula has been deduced as $\mathrm{C}_{30} \mathrm{H}_{46} \mathrm{O}_{4}$ from the positive mode of ESI TOF mass spectral data which indicated an $[\mathrm{M}+\mathrm{H}]^{+}$ion at $\mathrm{m} / z, 471.3462$ and this composition was further supported by the ${ }^{13} \mathrm{C}$ NMR spectral data. Compound 3 also showed a positive Liebermann-Burchard reaction indicating a terpenoid skeleton [13], as in $\mathbf{1}$ and $\mathbf{2}$. The ${ }^{1} \mathrm{H}$ NMR spectra of compound $\mathbf{3}$ also showed the presence of seven methyl sinlgets at $\delta 0.83,1.11,1.16,1.30,1.37,1.38$ and 1.43 ; a signal corresponding to the H-3 of the oxymethine proton which was appeared as a doublet of doublets at $\delta 3.52$; and a singlet at $\delta 6.04$ corresponding to the presence of a olefinic proton of an $\alpha, \beta$-unstaurated carbonyl group as in 2. In the absence of any anomeric proton together with appearance of 30 carbons in the ${ }^{13} \mathrm{C}$ NMR spectral data suggested the presence of an oleanane triterpene skeleton having a hydroxyl group at $\mathrm{C}-3$ position with a double bond at C-12/C-13 and seven methyl groups in its structure as in 2 . The ${ }^{1} \mathrm{H}$ and ${ }^{13} \mathrm{C}$ NMR values for all the protons and carbons were assigned on the basis of COSY, HSQC and HMBC correlations and were given in Table 1. In the absence of eighth methyl group and the appearance of a carbonyl group resonating at $\delta 179.6$ in the ${ }^{13} \mathrm{C}$ NMR spectral data of $\mathbf{3}$ as in $\mathbf{1}$ and $\mathbf{2}$ suggested the presence of an acid functional group at C-30 position. Based on the results from 1D and 2D NMR spectral data, it was concluded that the structure of $\mathbf{3}$ has a triterpene aglycone moiety with an $\alpha, \beta$-unsaturated carbonyl group, a carboxylic acid group, seven methyl singlets. Thus, the structure of $\mathbf{3}$ was assigned as the known compound $18 \beta$-glycyrrhetinic acid supported further by the key HMBC correlations as shown in Figure 3 as well by comparison of the spectral data to the reported from the literature [12].

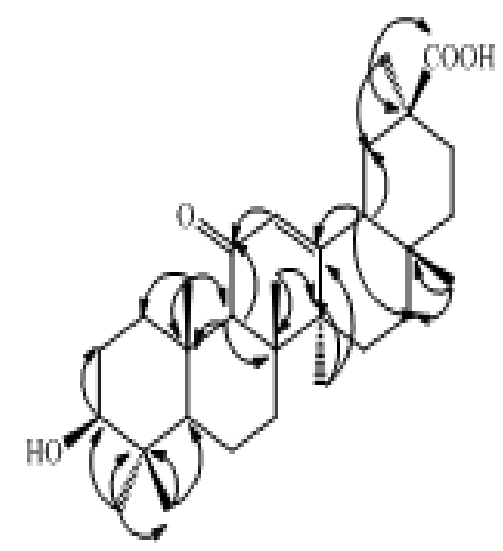

Figure 3: Key HMBC correlations of 18ß-glycyrrhetinic acid (3)

\section{CONCLUSIONS}

We are herewith reporting the isolation and complete ${ }^{1} \mathrm{H}$ and ${ }^{13} \mathrm{C}$ NMR spectral assignments for the two

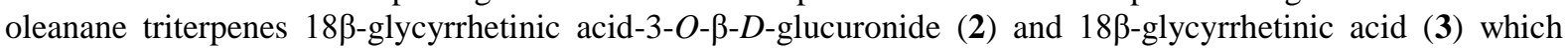
were isolated from the hydrolysis studies of the triterpene glycoside $18 \beta$-glycyrrhetinic acid-3-O- $\beta-D$ glucuronopyranosyl-( $(1 \rightarrow 2)-\beta$ - $D$-glucuronide $(\mathbf{1})$ which was isolated from the commercial extract of the roots of Glycyrrhia glabra. The proton and carbon assignments for compounds $\mathbf{2}$ and $\mathbf{3}$ were made on the basis of the extensive $1 \mathrm{D}$ and 2D NMR $\left({ }^{1} \mathrm{H}\right.$ and ${ }^{13} \mathrm{C}, \mathrm{COSY}, \mathrm{HSQC}$, and HMBC) as well as mass spectral data.

\section{REFERENCES}

[1.] Biondi, D.M., Rocco, C., Ruberto, G. Dihydrostilbene derivatives from Glycyrrhiza glabra leaves, Journal of Natural Products, 2005, 68, 1099-1102.

[2.] El-Refai, A.M.H., Sallam, A.R., El-Menoufy, H., Amin, H.A.S. Physiological and chemical studies on the bioconversion of glycyrrhizin by Aspergillus niger NRRL595, Malaysian Journal of Microbiology, 2012, 8, 75-82.

[3.] Nomura, T., Fukai, T., Akiyama, T. Chemistry of phenolic compounds of licorice (Glycyrrhiza species) and their estrogenic and cytotoxic activities. Pure and Applied Chemistry, 2002, 74, 1199-1206.

[4.] Akao, T. Effects of glycyrrhizin and glycyrrhetic acid on the growth, glycyrrhizin $\beta$-D-glucuronidase and $3 \beta$-hydroxysteroid dehydrogenase of human intestinal bacteria, Biological and Pharmaceutical Bulletin, 2000, 23, 104-107

[5.] Chaturvedula, V.S.P., Yu, O., Mao, G. (2013). NMR analysis and hydrolysis studies of glycyrrhizic acid, a major constituent of Glycyrrhia glabra, European Chemical Bulletin, 2014, 3, 104-107.

[6.] Chaturvedula, V.S.P., Chen, S., Yu, O., Mao, G. NMR spectral analysis and hydrolysis studies of rebaudioside N, a minor steviol glycoside of Stevia rebaudiana Bertoni. Food and Nutrition Sciences, 2013, 4, 1004-1008.

[7.] Chaturvedula, V.S.P., Chen, S., Yu, O., Mao, G. Isolation, NMR spectral analysis and hydrolysis studies of a hepta pyranosyl diterpene glycoside from Stevia rebaudiana Bertoni. Biomolecules, 2013, 3, 733-740.

[8.] Chaturvedula, V.S.P., Yu, O., Mao, G. Structural characterization of the hydrolysis products of rebaudioside M, a minor steviol glycoside of Stevia rebaudiana Bertoni. Journal of Chemical and Pharmaceutical Research, 2013, 5, 606-611. 
[9.] Chaturvedula, V.S.P., Yu, O., Mao, G. NMR Spectral Analysis of rebaudioside A, a major sweet diterpene glycoside of Stevia rebaudiana Bertoni at various temperatures, International Journal of Pharmaceutical Science Invention, 2013, 2, 36-40.

[10.] Chaturvedula, V.S.P., Ruo, H. Isolation and NMR spectral studies of dihydromyricetin, Journal of Pharmacognosy and Phytochemistry, 2013, 2, 113-115.

[11.] Li, L., Yang, Z., He-shui, Y., Hong-zhi, H., Li-ping, K., Man, C., Jiang-ming, C., Li-yan, Y., Xin-boo, S., Bai-ping, M.A. Preparation of glycyrrhetinic acid monoglucuronide by selective hydrolysis of glycyrrhizic acid via biotransformation, Chinese Herbal Medicines, 2012, 4, 324-328.

[12.] Rao, G.S.R., Kondaiah, P., Singh, S.K., Ravanan, P., Sporn, M.B. Chemical modifications of natural triterpenes-glycyrrhetinic acid and boswellic acids: evaluation of their biological activity, Tetrahedron, 2008, 64, 11541-11548.

[13.] An, R.B., Kim, H.C., Jeong, G.S., Oh, S.H., Oh, H., Kim, Y.-C. Constituents of the aerial parts of Agrimonia pilosa, Natural Product Sciences, 2005, 11, 196-198. 